\title{
Otomatisasi Pemilah Sampah Berbasis Arduino Uno
}

\author{
Andrian Eko Widodo', Suleman ${ }^{2}$ \\ ${ }^{1}$ Sistem Informasi, STMIK Nusa Mandiri \\ 2 Teknologi Komputer, Universitas Bina Sarana Informatika \\ 1andrian.aeo@nusamandiri.ac.id, 22suleman.sIn@bsi.ac.id
}

\begin{abstract}
The development of globalization and technology in the field of microcontrollers and sensors has an impact on human life. As in the field of cleanliness, the automation of waste segregation needs to be done based on the lack of concern for modern society towards waste. Waste sorting aims to separate waste based on the type of material (metal and non-metal) so that it is easier to take further action on existing waste such as recycling. In fact in various landfills various types of garbage are mixed into both metal and non-metal waste. This can reduce the quality of environmental health. For that reason, the writer tries to make an intelligent intelligent waste sorting design. With this tool the garbage can be sorted based on its type automatically using a proximity sensor. This tool works when garbage approaches the sensor then the sensor will read the type of object that is approaching. The detection results will be processed by Arduino UNO as a control system and the results of the process will be forwarded to the output in the form of an indicator of the type of garbage on the LCD 16x2 and servo as a drive of garbage to the place according to the type of waste..
\end{abstract}

Keywords: Trash, Automatic Trash Clustering Tool, Arduino, Proximity Sensor

Abstrak: Perkembangan globalisasi dan teknologi dibidang mikrokontroller dan sensor berdampak kepada kehidupan manusia. Seperti pada bidang kebersihan, otomatisasi pemilahan sampah perlu dilakukan didasari pada kurangnya kepedulian masyarakat modern terhadap sampah. Pemilahan sampah bertujuan untuk memisahkan sampah berdasarkan jenis bahan (logam dan non-logam) sehingga lebih mudah untuk melakukan tindakan lanjutan terhadap sampah yang ada seperti daur ulang. Pada kenyataanya di tempat pembuangan sampah berbagai jenis sampah bercampur menjadi satu baik sampah logam maupun nonlogam. Hal ini dapat menurunkan kualitas kesehatan lingkungan. Untuk itu penulis mencoba membuat rancang bangun alat pemilah sampah cerdas otomatis ini. Dengan alat ini sampah dapat dipilah berdasarkan jenisnya secara otomatis dengan menggunakan sensor proximity. Alat ini bekerja ketika sampah mendekati sensor kemudian sensor akan membaca jenis benda yang mendekat. Hasil deteksi akan diproses oleh Arduino UNO sebagai sistem control dan hasil proses akan diteruskan pada output yang berupa indicator jenis sampah pada LCD 16x2 dan servo sebagai penggerak sampah menuju tempat sesuai jenis sampahnya.

Kata kunci: Sampah, Pemilah Sampah Otomatis, Arduino, Sensor Proximity

\section{A. PENDAHULUAN}

Perkembangan di zaman era globalisasi dan teknologi dibidang mikrokontroler dan sensor berdampak kepada kehidupan manusia. Banyak sekali lahir berbagai inovasi teknologi baru dan terbarukan yang semuanya ditujukan untuk mempermudah dan membantu aktivitas manusia. Dengan perkembangan teknologi mikrokontroler dan sensor melahirkan alat bantu untuk meningkatkan kesadaran pentingnya menjaga kebersihan lingkungan. (Aritonang, Bayu, K, \& Prasetyo, 2017)

Definisi sampah menurut UU-18/2008 tentang Pengelolaan Sampah [68] adalah sisa kegiatan sehari-hari manusia dan/atau proses alam yang berbentuk padat. Sampah merupakan masalah yang sering menjadi trending topik dihampir semua negara berkembang. 
Menurut (Aritonang et al., 2017) mengatakan bahwa "Tercampurnya sampah logam dan nonlogam disatu wadah tempat sampah,yang berdampak kepada menurunnya kualitas lingkungan".

Dengan melakukan pengolahan sampah seperti pemilahan sampah, proses daur ulang sampah dan memanfaatkannya, diharapkan mampu mengurangi masalah-masalah dimasyarakat kita. Kondisi sampah yang ada di lingkungan di sekitar kita, saat ini sampahnya masih dalam kondisi tercampur jenisnya, belum dilakukan pemilahan sampah. Sehingga menjadi masalah ketika dilakukan daur ulang. (Almanda, Isyanto, \& Samsinar, 2018).

Berdasarkan permasalahan diatas, maka penulis tertarik untuk membuat alat pemilah sampah otomatis berbasis Arduino UNO. Alat ini dapat digunakan untuk memilah jenis sampah logam dan non logam untuk memudahkan proses recycle pada sampah yang masih bisa digunakan atau didaur ulang secara efisien sebelum sampai ke Tempat Pembuangan Akhir (TPA). Jika kondisi sampah tercampur jenisnya dan sudah sampai di TPA akan lebih sulit untuk proses daur ulang karena akan membutuhkan waktu dalam pemilahan sampah dan juga akan mempengaruhi kualitas sampah yang masih dapat didaur ulang. Dengan adanya alat ini diharapkan dapat membantu para aktivis peduli lingkungan maupun Usaha Kecil dan Menengah (UKM) yang memanfaatkan sampah untuk didaur ulang dan dijadikan suatu produk.

\section{B. TINJAUAN PUSTAKA}

\section{Arduino}

Menurut (Andrianto \& Darmawan, 2017) menyatakan bahwa "Arduino adalah suatu perangkat prototipe elektronik yang berbasis mikrokontroller yang fleksibel dan open-source, perangkat keras dan perangkat lunaknya mudah digunakan". Sedangkan menurut (Sanjaya, 2016) "Arduino dikatakan sebagai sebuah platform dari physical computing yang bersifat open source".

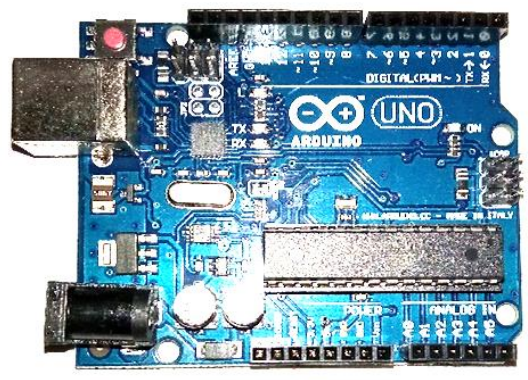

Sumber : https://store.arduino.cc/usa/arduinouno-rev3

Gambar 1. Board Arduino UNO

\section{IC (Integrated Circuit)}

Menurut (Hakiem, 2015) menggatakan bahwa "IC (Integrated Circuit) adalah komponen elektronika semi konduktor yang merupakan gabungan dari ratusan atau ribuan komponenkomponen lain".

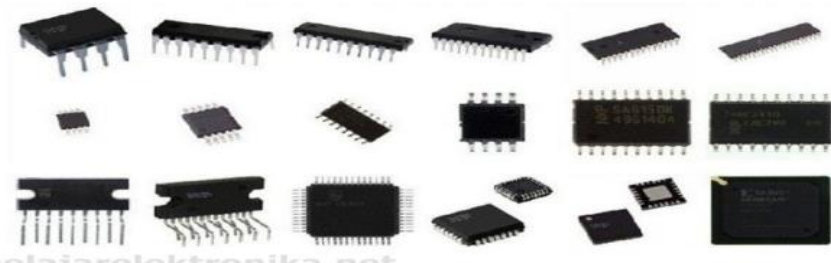

Sumber : belajarelekronika.net

Gambar 2. Bentuk Bentuk IC

\section{Sensor}

Menurut (Kadir, 2018) mengatakan bahwa "Sensor adalah peranti yang mengubah parameter fisik seperti temperatur, tekanan, kecepatan, atau kelembapan, menjadi isyarat listrik", dan menurut (Jati, 2018) "Sensor adalah jenis tranduser yang digunakan untuk 
mengubah besaran mekanis, magnetis, panas, sinar, dan kimia menjadi tegangan dan arus listrik".

Menurut (Kho, 2019) "Proximity Sensor (Sensor Proksimitas) atau dalam bahasa Indonesia disebut dengan Sensor Jarak adalah sensor elektronik yang mampu mendeteksi keberadaan objek di sekitarnya tanpa adanya sentuhan fisik".

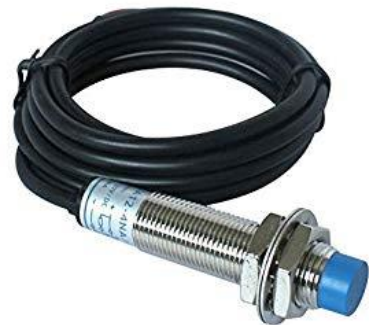

Sumber : www.amazon.in

\section{Motor Servo}

\section{Gambar 3. Proximity Sensor}

Menurut (Andrianto \& Darmawan, 2017) "Motor servo adalah sebuah motor dengan system umpan balik tertutup, posisi dari motor akan diinformasikan kembali kerangkaian control yang ada di dalam motor servo".

Sumber : Penulis

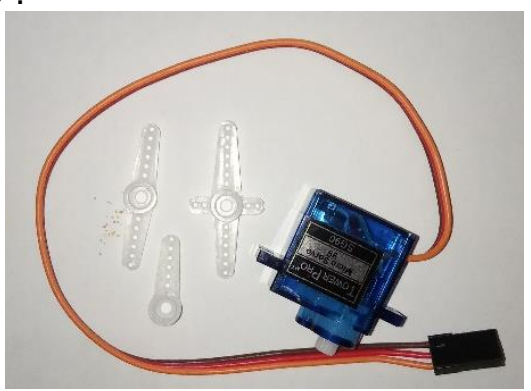

Gambar 4. Motor Servo

\section{LCD (Liquid Crystal Display)}

Menurut (Andrianto \& Darmawan, 2017) "LCD (Liquid Crystal Display) 16x2 adalah suatu display dari bahan cairan kristal yang pengoperasiannya menggunakan system dot matriks. LCD (Liquid Crystal Display) $16 \times 2$ dapat menampilkan sebanyak 32 karakter yang terdiri dari 2 baris dan tiap baris dapat menampilkan 16 karakter".

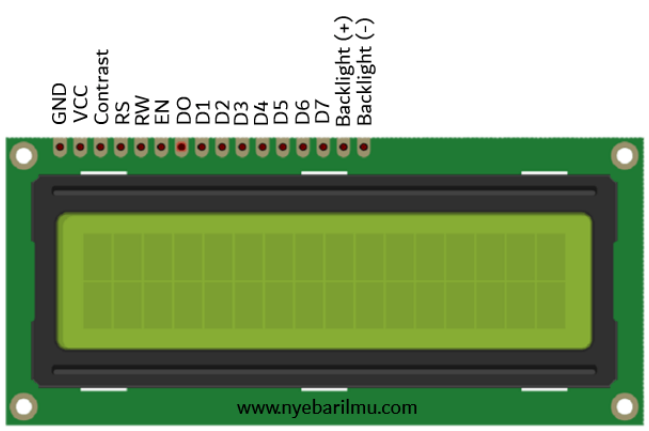

Sumber : www.nyebarilmu.com

Gambar 5. LCD 16x2

\section{Arduino IDE}

Menurut (Kadir, 2016) "Arduino IDE adalah tool yang bermanfaat untuk menuliskan program (yang secara khusus dinamakan sketsa di Arduino), mengompilasinya, dan sekaligus mengunggahkannya ke papan Arduino". Sedangkan menurut (Arduino, 2019) mengatakan "Arduino Software (IDE) - berisi editor teks untuk menulis kode, area pesan, konsol teks, bilah 
alat dengan tombol untuk fungsi umum dan serangkaian menu. Terhubung ke perangkat keras Arduino dan Genuino untuk mengunggah program dan berkomunikasi dengan mereka".

Sumber : Penulis

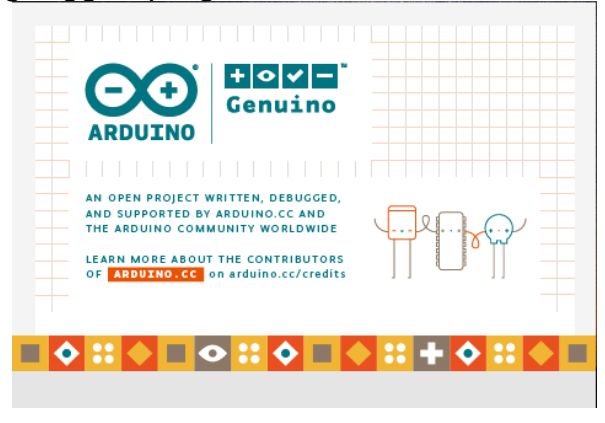

Gambar 6. Arduino IDE

\section{Sumber Tegangan}

Menurut (Nawali, Sherwin, \& Tulung, 2015) mendefinisikan bahwa "catu daya merupakan suatu rangkaian yang paling penting bagi rangkaian elektronika." Ada dua jenis sumber tegangan, yaitu:

a. Sumber AC (Alternating Current)

Sumber AC adalah sumber tegangan bolak-balik

b. Sumber DC (Direct Current)

Sumber DC adalah sumber tegangan searah. Sumber DC dapat diperoleh dari baterai.

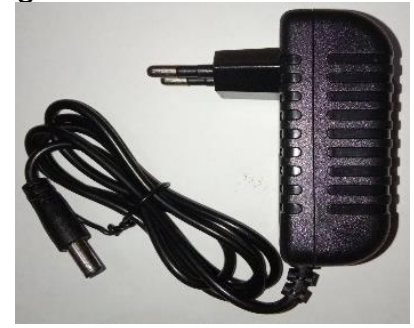

Sumber : Penulis

Gambar 7. Adaptor 12V DC 1A

\section{METODE PENELITIAN}

Metode penelitian yang digunakan dalam pembuatan alat ini adalah dengan beberapa metode, antara lain:

1. Metode Observasi

Penulis melakukan pengamatan langsung terhadap obyek yang berkaitan dalam pembuatan pembuatan alat pemilah sampah cerdas otomatis berbasis Arduino UNO.

2. Metode Studi Pustaka

Penulis mencari bahan referensi dari buku, jurnal-jurnal, literatur-literatur lainnya, dan artikel baik secara online maupun offline yang berhubungan dengan penelitian ini.

3. Metode Wawancara

Penulis melakukan wawancara dengan orang-orang yang memahami tentang masalah yang dibahas dalam pembuatan alat pemilah sampah cerdas otomatis berbasis Arduino UNO.

\section{HASIL DAN PEMBAHASAN}

\section{Tinjauan Umum Alat}

Alat pemilah sampah otomatis adalah sebuah alat yang berguna untuk memilah sampah secara otomatis berdasarkan jenis sampah tersebut. Jenis sampah yang dideteksi oleh alat ini adalah jenis sampah logam dan non-logam yang kemudian akan ditampilkan dalam bentuk tulisan yang berupa keterangan dalam sebuah LCD.

Pemilahan sampah yang dilakukan bertujuan untuk mempermudah proses recycle sampah yang masih bisa didaur ulang. Untuk itu, alat ini dapat digunakan sebagai alternatif untuk pemilahan sampah sebelum sampai ke TPA (Tempat Pembuangan Akhir). 


\section{Blok Rangkaian Alat}

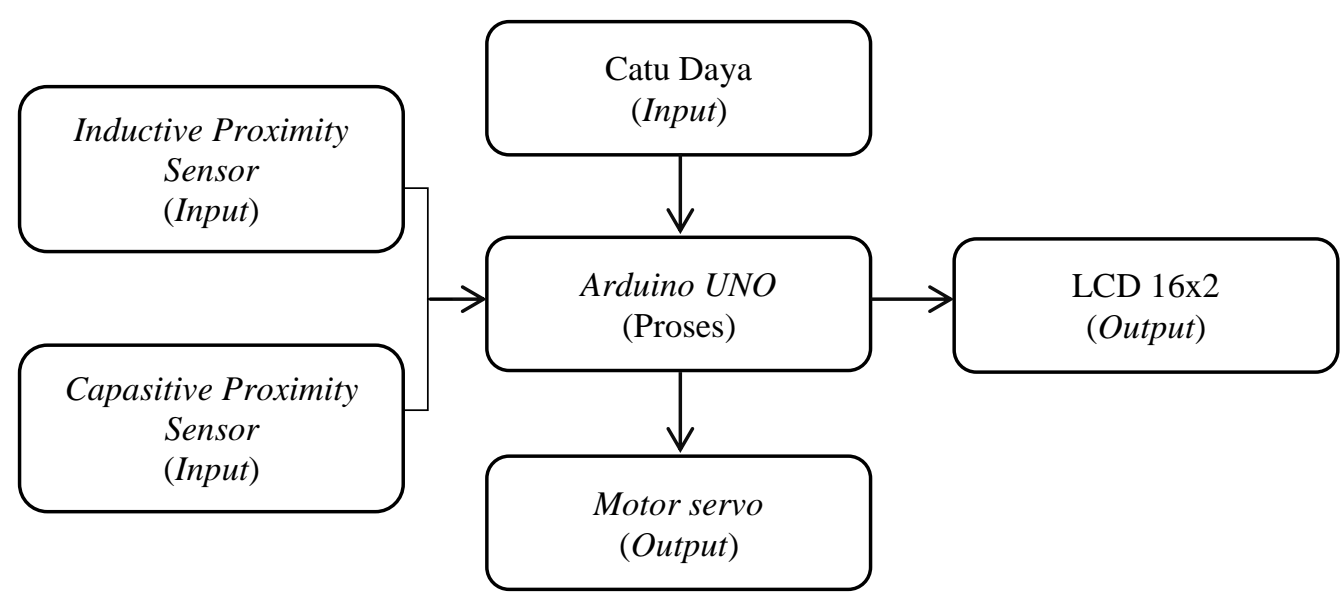

Sumber : Penulis

Gambar 8. Blok Rangkaian Alat

Pejelasan blok rangkaian alat ini adalah:

a. Input

Input merupakan masukan yang nantinya akan diolah oleh pemroses. Dalam alat ini ada 2 komponen input yang terdiri dari :

1) Catu daya berupa adaptor $+12 \mathrm{~V}$ yang akan menyalurkan arus listrik kedalam rangkaian alat.

2) Proximity sensor yang berfungsi untuk mendeteksi jenis sampah logam maupun nonlogam.

b. Proses

Proses merupakan komponen yang sangat penting dalam alat ini. Berfungsi sebagai pengolah atau pemroses data yang masuk dari input-an dalam hal ini adalah proximity sensor dan kemudian akan menampilkan hasilnya berupa tampilan pada LCD dan servo. Dalam pembuatan alat ini, penulis menggunakan Arduino UNO sebagai alat pemrosesnya.

c. Output

Output merupakan hasil akhir dari masukan yang sudah diproses. Dalam pembutan alat ini penulis menggunakan motor servo dan LCD $16 \times 2$ sebagai output dari proses yang telah dilakukan.

\section{Skema Rangkaian Alat}

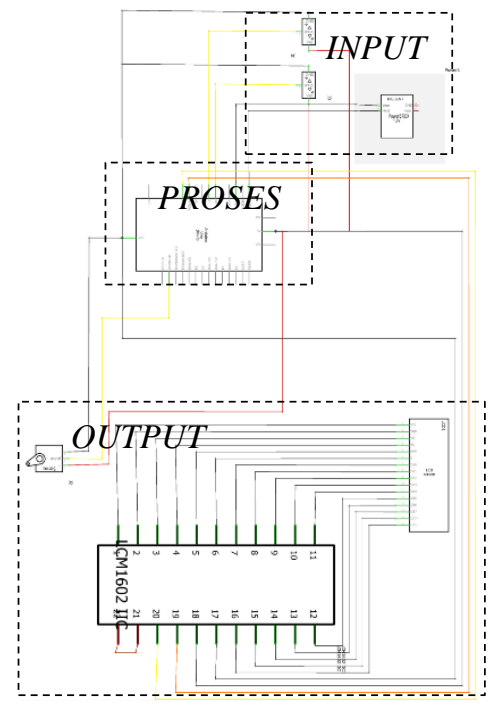

Gambar 9. Skema Rangkaian Alat 
Skema rangkaian alat ini terdiri dari rangkaian input, proses, dan output. Rangkaian input dalam alat ini terdiri dari catu daya berupa adaptor $12 \mathrm{~V}$ dan sensor proximity yang mendeteksi jenis sampah logam dan non-logam. Proses dalam rangkaian alat ini menggunakan Arduino UNO, yaitu dengan mengolah hasil data dari sensor proximity. Sedangkan untuk rangkaian output dalam alat ini berupa tampilan hasil proses dengan menggunakan LCD 16x2 dan motor servo sebagai penggerak untuk mengarahkan sampah ke wadah sampah sesuai jenisnya.

\section{Flowchart}

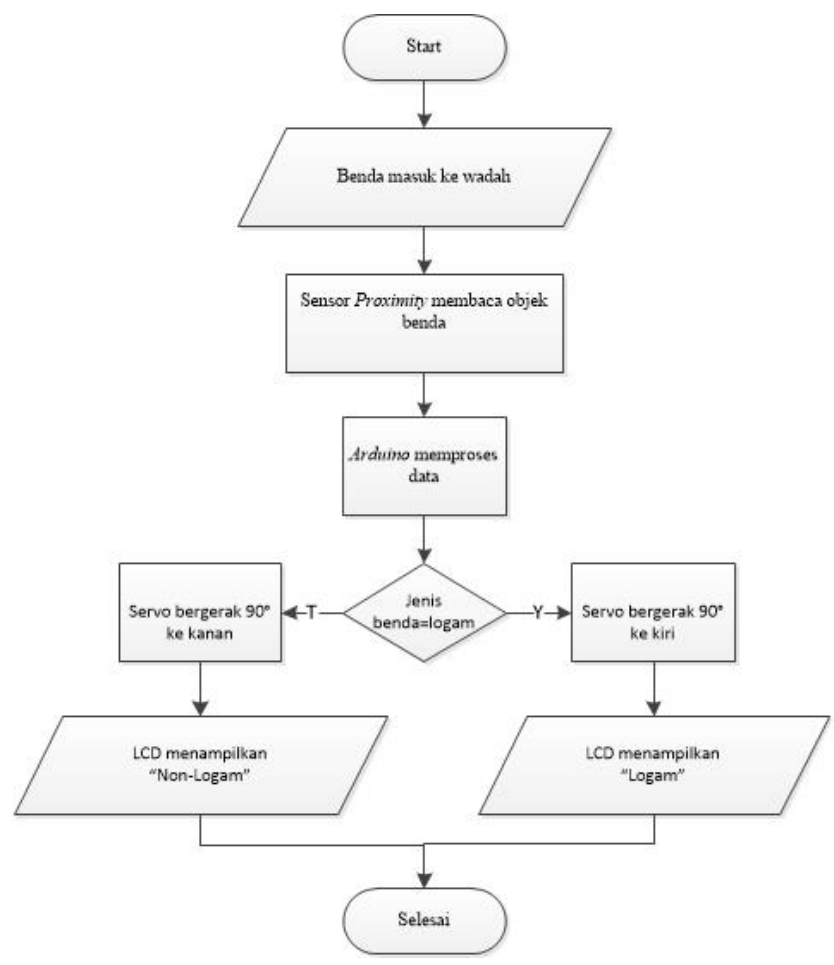

Gambar 10. Flowchart

\section{E. KESIMPULAN}

Dari hasil pembuatan alat pemilah sampah otomatis berbasis Arduino UNO ini, dapat diambil kesimpulan bahwa alat ini memilah sampah logam dan non-logam dengan memanfaatkan sensor proximity yang berfungsi untuk mendeteksi jenis sampah. Sensor proximity digunakan untuk mendeteksi jenis sampah yang berbahan logam, dan non-logam. Alat ini dapat memilah jenis sampah dengan jarak sensor dan benda (sampah) dengan jarak maksimal $0,5 \mathrm{~cm}$ agar sensor dapat mendeteksi dengan baik. Kelemahan pada alat ini hanya bisa mendeteksi jenis sampah satu per satu. Belum bisa memilah sampah dengan kondisi sampah yang berada dalam wadah, misalnya di dalam sebuah kantong plastik.

\section{REFERENSI}

Almanda, D., Isyanto, H., \& Samsinar, R. (2018). Perancangan Prototype Pemilah Sampah Organik Dan Anorganik Menggunakan Solar Panel 100 Wp Sebagai Sumber Energi Listrik Terbarukan. Seminar Nasional Sains Dan Teknologi, 1-9.

Andrianto, H., \& Darmawan, A. (2017). ARDUINO Belajar Cepat dan Pemrograman. Bandung: Informatika Bandung.

Arduino. (n.d.). Arduino. Retrieved July 15, 2019, from 
https://www.arduino.cc/en/Guide/Environment

Aritonang, P. L. E., Bayu, E. C., K, S. D., \& Prasetyo, J. (2017). Rancang Bangun Alat Pemilah Sampah Cerdas Otomatis. Snitt, https://doi.org/10.1016/j.contraception.2014.02.009

Hakiem, I. (2015). Tokoteknologi: Electronics Design \&amp; Repair - Tokoteknologi Mikroelektronik Nusantara - Google Books (Ilmiawan Hakiem, Ed.). Retrieved from https://books.google.co.id/books?id=DIQvCwAAQBAJ\&pg=PT4\&dq=pengertian+ic\&hl=en \&sa $=$ X\&ved=0ahUKEwj3nNTrq5PjAhXE6XMBHbP-

DxEQ6AEIKDAA\#v=onepage\& $q \& f=$ false

Jati. (2018). Pengertian, macam macam,Jenis, sensor penjelasan Contoh Gambar. Retrieved July 10, 2019, from https://www.jatikom.com/2018/11/macam-macam-sensorpenjelasannya-gambar.html

Kadir, A. (2016). Simulasi Arduino - Abdul Kadir - Google Books. Retrieved from https://books.google.co.id/books?id=yC1IDwAAQBAJ\&pg=PA2\&dq=arduino+IDE+adalah\& $\mathrm{hl}=\mathrm{en} \& s a=X \& v e d=0$ ahUKEwjn76L6kbbjAhWlv48KHXggAisQ6AEIMjAB\#v=onepage \&q=ar duino IDE adalah\& $f=f a l s e$

Kadir, A. (2018). Belajar Sendiri Pasti Bisa: ARDUINO (M. Kika, Ed.). Yogyakarta: Penertbit ANDI.

Kho, D. (2019). Pengertian Proximity Sensor (Sensor Jarak) dan Jenis-jenis Proximity Sensor. Retrieved July 10, 2019, from https://teknikelektronika.com/pengertian-proximity-sensorsensor-jarak-jenis-jenis-sensor-proximity/

Nawali, E. dedy, Sherwin, \& Tulung, N. M. (2015). Rancang Bangun Alat Penguras Dan Pengisi Tempat Minum Ternak Ayam Berbasis Mikrokontroler Atmega 16. E-Journal Teknik Elektro Dan Komputer Vol.4 No.7 (2015), ISSN : 2301-8402, 4(7), 25-34.

Sanjaya, M. (2016). Panduan Praktis Membuat ROBOT CERDAS menggunakan ARDUINO dan MATLAB (Ignas, Ed.). Yogyakarta: Penertbit ANDI. 